\title{
Study on Landslide Surge in Reservoir Area
}

\author{
Han Kai, Peng Hui, Wu Fan, Yin Shaofei and Li Wenguang \\ College of Hydraulic \& Environmental Engineering, China Three Gorges University, Yichang 443002, China
}

\begin{abstract}
Landslide surge is a fluid-solid coupling problem involving multidisciplinary intersections such as landslide dynamics, fluid mechanics and mechanics along the way, which has important research value. The construction of the reservoir will affect the natural geological conditions of the slope of the reservoir area, slope rock under the joint effect of the waves and the reservoir water level changes, which will cause the reservoir bank collapse and even landslides. The occurrence of landslide will cause some loss. In this paper, the types of landslide generation, disaster classification, research methods and existing problems are reviewed. It makes people understand the basic research ideas of landslide surge. Through the analysis and discussion of the different research methods of landslide surges, the shortcomings of these analytical methods are analyzed, which provide important basis for future research and indicate the future research methods and direction.
\end{abstract}

Key words: Landslide surge, method, problem, prospect.

\section{Introduction}

Reservoir landslide is due to bank slope instability caused by a large number of landslides into the water at high speed, resulting in a huge surge. And the slippery water into the water may cause a huge surge to threaten sailing vessels and reservoir residents along the bank life and property safety, and even worse the impact of dam safety and the risk of dam break, resulting in huge economic loss [1]. Especially in the near dam, high-speed landslide has the greatest harm to the reservoir [2, 3].

As in 1963, the left bank of Italy Wayi Ang reservoir landslides [4], resulting in surging higher than the crest $125 \mathrm{~m}$, about 25 million cubic meter of reservoir water over the crest, destroyed the lower reaches of Longjiaro city and its downstream several villages and caused more than 2,000 deaths. In 1985, the New Beach landslide occurred in Zigui county, Hubei province [5]. The loose rock and gravel with a volume of about 18.8 million cubic meter slipped, of which about 3.4 million cubic meter slide into the water, resulting in up to $49 \mathrm{~m}$ of torrent. Lacking of

Corresponding author: Peng Hui, professor, main research field: hydraulic engineering. prediction of the spread of the surge, the surge caused by $7 \mathrm{~km}$ upstream of more than 70 ship damages. The existence of landslide not only increases the difficulty of early warning of the collapse of the reservoir, but also greatly increases the scope of the reservoir landslide warning.

\section{Classification and Disaster}

In the form, landslide is different. According to the landslide out of the water surface of this part of the movement, landslide will be divided into splash form, the former form and post-collapse shape [6]. According to the Froude numerical range, the initial form is divided into conventional surge, the surge passage and jump red surge.

Landslide hazard is the surface water waves caused by landslides, landslides, etc. and internal shock waves or catastrophic events. Landslide caused by the disaster can be divided into four cases:

(1) Landslide damage to the area of personal property losses. Once the collapse of the bank slope occurred, the first impact is the area between the landslide and the river surface, which is called the landslide failure zone. As the New Beach landslide, the town was destroyed and it would inevitably cause 
a lot of casualties.

(2) The impact of landslides on ships and both sides. Landslide into the water will produce a huge surge and cause a great horizontal flow rate. The waters of the region will be a huge impact on the ship and damage and the two sides of the mountain will be subject to varying degrees of impact.

(3) On the flow conditions of the channel. Surge up and down, the downstream waters of the spread, a large horizontal flow rate and the formation of local reflow and backflow deteriorate the flow conditions along the channel, affecting shipping.

(4) Damage to the dam. Surge on the dam area, on the one hand, the dam will be a larger kinetic energy of the impact of the dam on the stability of the threat; on the other hand, the surge will produce a larger wave climb. The top of the dam itself and the structure of the lower dam will cause greater harm [7].

\section{Methods}

There are two key points in the analysis and evaluation of the destructive analysis of surge: predicting the height of the formation of waves and the propagation process of the attenuation law. At present, the research methods of landslide surge at home and abroad are as: (1) numerical simulation method; (2) empirical formula method; (3) model test formula method; (4) theoretical analysis method. These research methods have different advantages and disadvantages and this article will briefly introduce a variety of research methods.

\subsection{Numerical Simulation Method}

The numerical simulation technology of landslide hazard is an important research method to carry out related work at home and abroad. The method can analyze the surging disaster more comprehensively, and it is accurate, economical and reasonable [8]. The numerical simulation method is mainly based on the shallow water equation and the Navier-Stokes equation. The simulation method based on the shallow water equation can describe the generation and propagation process of the surge. However, the empirical parameters are more and some parameters are difficult to be determined in the practical problem. The simulation method based on Navier-Stokes equations requires less empirical parameters and has an essential advantage in describing strong nonlinear water waves. Numerical simulation analysis can be divided into finite element method, finite difference method and boundary element method. It often uses $\mathrm{N}-\mathrm{S}$ equation to solve problems [9].

The shallow water control equation is used to simulate the landslide and the control equation is solved by a simple and highly accurate two-step Taylor-Galerkin method. Some scholars use the CFD (Computational Fluid Dynamics) method to simulate the process of surge generation of landslide into the water. The simulation method adopts the integrated method. The sliding process is regarded as rigid body and the sliding body enters the water and is regarded as the fluid material.

In the simulation of two-dimensional mathematical model of landslide surge, the influence of free surface boundary is considered. The calculation method of free surface is mainly MAC (Marker and Cell) method and VOF (Volume of Fluid) method [10]. On the basis of this, the continuous equation and Navier-Stokes equations are used to derive the landslide surge control equation, and then establish the mathematical model of landslide surge [11, 12]. In addition, the continuous equation and the Navier-Stokes equations can be solved by SPH (Smoothed Particle Hydrodynamics) method to establish the SPH numerical model.

\subsection{Empirical Formula Method}

The empirical formula method is mainly based on field observation and engineering practice analogy, similar to the engineering geology analogy. Its objective control factors are less, subjective judgment mostly and the formula has less influence parameter. 
The empirical formula method is based on the analysis of the limited landslide survey data. The researchers summarized the dimensionless calculation function. But the statistical induction samples are less accurate and applicable. The accuracy and applicability of the study is more difficult to judge.

In the country, empirical formula method is mainly used to study the spread of landslide. It mainly studies the landslide propagation in the reservoir area and rarely used in the study of underwater landslides or submarine landslides. From the type of wave, the landslide wave is a nonlinear shallow wave. The propagation and climbing of landslide waves can be calculated using the Boussinesq equation and the NSWW (Nonlinear Shallow Water Wave) model equation. The Boussinesq model can effectively simulate the high amplitude and short wavelength surge, and can well reproduce the influence of the bank on the waves and provide more realistic landslide simulation results.

\subsection{Model Test Formula Method}

In the design of the physical model test, the geometric similarity should be met. The similarity of the water flow and the dynamic similarity follow the Froude similarity criterion, and the landslide body should meet the geometric similarity and the similarity of the block, and the river and the bank should meet the similarity.

At present, domestic and foreign scholars on the landslide surge physical model test research focused on the landslide into the water process changes in the surge, the maximum surge height and propagation of the study. It is of great theoretical and practical significance to study the wave height and its propagation attenuation law of the surging waves by physical model test method, which is similar to the actual situation. Beginning with Russell, a large number of researchers conducted a generalized physical model tests [13]. These generalization models can be divided into block model, granular slide model, piston model and other models. The block model is modeled by a large number of models. The block in the block model is slid into the water in a frictionless slope. Some scholars carried out the block surge test and summed up the first wave calculation formula [14]. Some landslides promoting the model of the water body can be simplified as the piston model. When the landslide body is located in the river bed and the slippery body thickness is greater than the water body, the role of the landslide body and the water can be simplified as the piston to promote the water.

\subsection{Theoretical Analysis Method}

Theoretical analysis is derived from the assumption of linearization and simplification, so it is difficult to analyze the complex nonlinear surge process. It only considers the small amplitude wave and linear wave, so the results can only be used for early assessment of landslide surge. Noda began to carry out the theory of surge theory earlier [15]. He made the original complex water wave formula linearization and simplified the formation of the Noda water wave analysis [15]. On the basis of Noda method, experts and scholars at home and abroad have improved the formation of the American Civil Engineering Society recommendation method, Pan Jiazheng law and several domestic versions of the Pan Jiazheng improvement method [16]. Due to the lack of prototype observations, domestic and foreign scholars actively carry out physical generalization experiments to explore the mechanism of surge generation and numerical simulation research worth further, but the premise must obtain accurate calculation parameters.

The above methods have their own advantages and some limitations. Future research may combine the advantages of various methods to find a more reasonable and more optimized method to analyze the landslide problem. 


\section{Analysis and Discussion}

In the actual situation, the formation of reservoir landslide surge is affected by many factors, and most of the current research on surging at home and abroad is too simplistic, with a large deviation from the actual situation, or for a landslide has occurred in a case research, boundary conditions and initial conditions are fixed, and the application is not strong. From the above research situation, there are many methods of landslide research at home and abroad, but each method has different degree of defects:

(1) Model test formula method: The use of the sink is too wide to consider the river form and water constraints and the trough section of the same shape. It does not distinguish between river and dam surface distribution characteristics. The model test is comprehensive, but it is not deep enough in the study of river channel shape, and the river is mostly rectangular. Many model tests are only for a specific project, and the application is not strong. Although the model is geometrically similar to the principle of production, it is different with the actual river and landslide body size. The types of landslide materials used in the test are limited and can not reflect the relevant properties of the bulk continuum as a whole. Therefore, some problems need further study.

(2) Theoretical analysis method: It lacks the actual landslide data and there is no more landslide data to carry out theoretical analysis. Landslide surge observation and detection is difficult and does not get accurate monitoring data, which may lead to theoretical analysis of errors. The theoretical analysis of landslide surge is difficult to verify and there is no good means and method of verification.

(3) Empirical formula method: Due to terrain, geomorphology and geological differences, landslides are also different forms, resulting in a more different mechanism of movement. Many times it cannot use completely analogous way to study the different landslides. It is difficult to experience the promotion.

(4) Numerical simulation method: On the one hand, it improves the efficiency of three-dimensional analysis. On the other hand, it needs to further understand how the sliding body interacts with water and air, how the $\mathrm{N}-\mathrm{S}$ equation solves the iterative efficiency and how to get the calculated parameters.

These are the problems and limitations of these methods which need to study and improve.

\section{Conclusions}

(1) In the study of landslide sliding process simulation, the physical and mechanical properties of landslide body are described by considering different types of slope sliding instability mechanism, and the fluid control equation is used to simulate the sliding process of loose bulk. For block landslides, the problem of motion contact between discrete blocks should be studied and a motion model that reflects the interaction between blocks can be established to simulate the sliding problem of block landslides.

(2) By combining with the current results of geographic information and the results of the analysis of the bank depression, it achieves the cross application between different disciplines, finds new research methods and realizes accurate and rapid modeling and analysis.

(3) For the landslide caused by the landslide, it is often considered that the slider is stopped at the stage after water entry. Therefore, there is some error in calculating the drop height. In the future, the initial conditions should be further precise. At the same time, the actual path of the landslide movement should be calculated for the continuous movement of the underwater water. The impact of the underwater sliders on the water body should be given sufficient consideration and calculation correction.

(4) Due to the complexity and randomness of landslide occurrence, it needs to consider the deformation of the slippage body, the volume of the sliding body and the effect of the continuous decline of the multi-block on the water surface after the sudden separation of the slippers. These are worthy of 
further study.

(5) It is also worthwhile to study the influence process of the landslide into the dam after the flooding.

\section{References}

[1] Wang, Y. D. 2005. "Reservoir Bank Landslide Velocity and Its Surging Disaster.” Ph.D. thesis, China University of Geosciences.

[2] Wang, L. S. 2007. "Investigation of Landslide in Vaayung Reservoir, Italy.” Journal of Geological Hazards and Control 3: 145-8.

[3] Wang, D. Y., and Liu, S. K. 1986. "Study on Surge Investigation of Yangtze Xintan Landslide (June, 1985).” People's Yangtze 10: 24-7.

[4] Zhang, Z. 2013. "Numerical Simulation of Typical Landslide Surge in a Power Station Area." Water Resources and Hydropower Engineering 6: 41-3.

[5] Yuan, J., and Zhang, X. F. 2008. "Numerical Simulation of Reservoir Landslide under Variable Grid.” Advances in Water Science 4: 546-51.

[6] Yue, S. B., Diao, M. J., and Wang, L. 2016. "The Initial Form of Landslide and Its Attenuation Law.” Journal of Hydraulic Engineering 6: 816-25.

[7] Jiang, Z. B., Jin, F., and Sheng, J. 2005. "Numerical Simulation of Water Waves due to Landslides.” Journal of Yangtze River Scientific Research Institute 22 (5): 1-3.

[8] Huang, P. L., Yin, Y. P., and Chen, X. T. 2014. "Review of
Geological Disaster Surge.” Progress in Geology and Geology 6: 112-8.

[9] Heller, V., and Hager, W. H. 2011. "Wave Types of Landslide Generated Impulse Waves.” Ocean Engineering 38 (4): 630-40.

[10] Zhou, G. Y., and Li, T. C. 2013. "Finite Numerical Simulation of Surge Propagation in Reservoir Landslide.” Rock and Soil Mechanics: 1197-201.

[11] Song, X. Y., Xing, A. G., and Chen, L. Z. 2009. "Numerical Simulation of Two-Dimensional Landslide Surge Based on FLUENT.” Hydrogeology and Engineering Geology 3: 90-4.

[12] Liu, X., Tan, G. H., and Wang, D. G. 2013. "Numerical Simulation of Landslide Surge in Reservoir.” Journal of Ship Mechanics: 75-83.

[13] Luo, X., Li, Y., and Zhou, S. L. 2013. "Landslide Generated Wave Theory in Reservoir Areas.” Journal of Chongqing Jiaotong University 32: 3481-4.

[14] Wang, X. H., and Liu, H. C. 1996. “A Two-Dimensional Fem Analysis on Surge Induced by Landslide.” Journal of Geological Hazards and Environment Preservation 4.

[15] Bao, Y., and Tang, X. J. 2011. "Calculating Sliding Speed and Surge Height of Unstable Slopes in a Reservoir.” Journal of Geological Hazards and Environment Preservation 1: 009.

[16] Ma, X. L., and Xia, M. 2015. "Review on Forecast Evaluation Methods of Landslide Surge.” Journal of Advances in Science and Technology of Water Resources 35: 389-98. 